\title{
Immunogenetic status and breeding value of Holstein cows
}

\author{
Vladimir Kaishev ${ }^{1}$, Anzor Zhilyaev², Tamirlan Kudaev², Madina Tleinsheva ${ }^{2}$, and Ibragim \\ Taov $^{2}$ \\ ${ }^{1}$ Federal State Budgetary Educational Institution of Higher Education Southern Federal University, \\ 105/42 B. Sadovaya Str., 344006 Rostov-on-Don, Russia \\ ${ }^{2}$ Kabardino-Balkarian State Agricultural University named after V. M. Kokov, Lenin Avenue, 1V, \\ 360030 Nalchik, Russia
}

\begin{abstract}
In the genealogical structure of the breeding stock, the highest specific weight is occupied by the Reflection Sovering and Vis bek Aydiala lines, accounting for 56.8 and $39.9 \%$ of animals, respectively. The study results of Holstein cattle blood-group factors can be used to monitor its gene pool, genetic intrabreed differentiation, assess selection parameters, and conduct targeted selection of parental pairs. It was determined that in EAA blood group system in Holstein cows of reproduction from the USA, the frequency of A1 antigen is $58.7 \%$, and in domestic reproduction animals, this antigen is found with a lower frequency of $50.7 \%$. At the same time, in the specified system of blood groups in both groups of experimental animals, antigen "a" is characterized by the highest frequency, the lowest occurrence is A2 antigen, and animals with $\mathrm{A} 1$ antigen took an intermediate position. In EAB system, the US Holstein cows have a higher frequency of such antigens as $\mathrm{E}_{3}{ }^{\prime}, \mathrm{O}_{3}$ и $\mathrm{I}_{1}$ compared to the reproductive animals of Agro-Soyuz LLC. The EAF blood group system is represented by two antigens, where $\mathrm{F}$ antigen frequency in both groups of experimental animals is $100 \%$. Of all the blood group systems, the greatest differences between compared groups of animals were detected for the antigens of EAZ blood group system.
\end{abstract}

\section{Introduction}

Within the framework of "Agro-Industrial Complex Development" national project implementation in the republics of the North Caucasus region, Holstein breed animals are imported from various countries, distinguished by high indicators of productivity. Under new conditions the imported animals are characterized by high productivity rates, which is due, along with the genotype, to paratypical factors $[1,2,3,4,5,6,7,8,9]$. At the same time, the problem of a more complete implementation of the productivity potential of imported animals and its preservation in subsequent generations, considering adaptation to new conditions of feeding and keeping, determination of immunogenetic status of animals of the Holstein breed remains relevant. 


\section{Materials and methods}

To assess the hereditary qualities and breeding value of Holstein breed animals, we analyzed the data on the productivity of the female ancestors of stud bulls. For this purpose, we used the method of N.A. Kravchenko (1973) on the assessment of the origin and determination of breeding indices [10]. To study the immunogenetic status of cows in the laboratory of immunogenetics, biochemistry and general chemistry of the State Scientific Institution "Stavropol Scientific Research Institute of livestock breeding and forage production", blood group systems and antigenic differences (antigens belonging to 7 blood group systems) were determined according to generally accepted method in 75 Holstein cows imported by heifers from the USA, as well as from daughters received under conditions of Agro-Soyuz LLC. The actual frequency of individual antigens was calculated by the ratio of the number of animals, carrying this antigen, to the total number of individuals in the group.

\section{Results and discussion}

To characterize animal hereditary qualities of the Holstein breed, we analyzed genealogical structure data of the breeding stock of Agro-Soyuz LLC. It was determined that In the genealogical structure of the breeding stock, the highest specific weight is occupied by the Reflection Sovering and Vis bek Aydiala lines, accounting for 56.8 and $39.9 \%$ of animals, respectively. The share of other lines in the herd structure is insignificant. The used stud bulls of these lines are characterized by a high genetic potential of milk productivity, high hereditary inclinations of the productivity of female ancestors, they improve such features as milk yield, body type and protein-milk content. Parental indices of Holstein bulls ranged in milk yield from 10806 to $13718 \mathrm{~kg}$, in fat and milk content in the range of $3.65-4.47 \%$ and $3.17-3.5 \%$. Differences between analyzed animals were revealed in terms of the parental index of the bull, due to linear affiliation. Thus, Holstein breed bulls of the Reflection Sovering line exceeded the bulls of the Vis Bek Aydiala line in milk yield by $0.86 \%$, in terms of the mass fraction of fat and protein - by 0.04 and $0.04 \mathrm{abs} . \%$, in terms of the total amount of milk fat and protein - by 11.0 and $8.0 \mathrm{~kg}$, or 2.3 and $2.05 \%$, respectively.

The study of blood-group factors in Holstein cattle is an urgent task, because the results obtained can be used to monitor its gene pool, genetic intrabreed differentiation and assessment of selection parameters, conduct targeted selection of parental pairs, and also supplement the available materials on breeding and improving this breed.

To characterize blood groups, as well as the immunogenetic status of Holstein cattle, the frequency of antigens was studied (Table 1).

Table 1. Frequency of antigens in Holstein cows $(n=75)$.

\begin{tabular}{|c|c|c|c|c|c|}
\hline \multirow{2}{*}{ Blood group system } & \multirow{2}{*}{ Antigen } & \multicolumn{2}{c|}{ Number of animals with antigen } & \multicolumn{2}{c|}{ Antigen frequency, \% } \\
\cline { 2 - 6 } & & Cows & Heifers & Cows & Heifers \\
\hline \multirow{3}{*}{ EAA } & $\mathrm{A}$ & 44 & 38 & 58.7 & 50.7 \\
\cline { 2 - 6 } & $\mathrm{A} 2$ & 15 & 20 & 20.0 & 26.7 \\
\cline { 2 - 6 } & $\mathrm{a}$ & 57 & 56 & 76.0 & 74.7 \\
\hline \multirow{5}{*}{$\mathrm{EAB}$} & $\mathrm{E}_{3}{ }^{\prime}$ & 26 & 21 & 34.7 & 28.0 \\
\cline { 2 - 6 } & $\mathrm{I}_{2}$ & 29 & 30 & 38.7 & 40.0 \\
\cline { 2 - 6 } & $\mathrm{Y}_{2}$ & 47 & 45 & 62.7 & 60.0 \\
\cline { 2 - 6 } & $\mathrm{Q}$ & 43 & 44 & 57.3 & 58.7 \\
\cline { 2 - 6 } & $\mathrm{I}_{1}$ & 32 & 25 & 42.7 & 33.3 \\
\cline { 2 - 6 } & $\mathrm{G}_{2}$ & 13 & 17 & 17.3 & 22.7 \\
\hline
\end{tabular}


Table 1. Continued

\begin{tabular}{|c|c|c|c|c|c|}
\hline \multirow{5}{*}{ EAB } & $\mathrm{O}^{\prime}$ & 53 & 53 & 70.7 & 70.7 \\
\hline & $\mathrm{O}_{3}$ & 50 & 45 & 66.7 & 60.0 \\
\hline & $\mathrm{G}^{/ /}$ & 1 & 3 & 1.3 & 4.0 \\
\hline & $\mathrm{O}_{2}$ & 3 & 5 & 4.0 & 6.7 \\
\hline & $\mathrm{P}^{1}$ & 10 & 19 & 13.3 & 25.3 \\
\hline \multirow{5}{*}{ EAC } & $\mathrm{X}_{2}$ & 27 & 28 & 36.0 & 37.3 \\
\hline & $\mathrm{C}_{1}$ & 58 & 57 & 77.3 & 76.0 \\
\hline & $\mathrm{C}_{2}$ & 38 & 32 & 50.7 & 42.7 \\
\hline & $\mathrm{W}$ & 13 & 17 & 17.3 & 22.7 \\
\hline & $\mathrm{R}_{2}$ & 36 & 36 & 48.0 & 48.0 \\
\hline \multirow{2}{*}{ EAF } & $\mathrm{V}$ & 5 & 4 & 6.7 & 5.3 \\
\hline & $\mathrm{F}$ & 75 & 75 & 100 & 100 \\
\hline \multirow{4}{*}{ EAS } & $\mathrm{H}^{\|}$ & 11 & 13 & 14.7 & 17.3 \\
\hline & $\mathrm{S}_{1}$ & 25 & 26 & 33.3 & 34.7 \\
\hline & $\mathrm{H}^{\mid}$ & - & - & & \\
\hline & $\mathrm{U}^{\|}$ & - & - & & \\
\hline \multirow{2}{*}{ EAZ } & $\mathrm{Z}$ & 19 & 35 & 25.3 & 46.7 \\
\hline & $\mathrm{Z}$ & 53 & 108 & 70.7 & 144.0 \\
\hline EAT & $\mathrm{T}_{2}$ & 3 & 4 & 4.0 & 5.3 \\
\hline
\end{tabular}

It was found that EAA blood group system is represented by 3 antigens, they have different frequency, due to the genotype of the compared animals. Thus, in Holstein cows of reproduction from the USA, the frequency of A1 antigen is $58.7 \%$, and in domestic reproduction animals, this antigen is found with a lower frequency of $50.7 \%$. In this system of blood groups, A2 antigen occurs with a frequency of $20.0 \%$ in imported animals. In comparison, the proportion of animals with A2 antigen is $26.7 \%$. Along with this, in both groups of experimental animals, the same occurrence of "a" antigen is observed, which is 76.0 and $74.7 \%$, respectively. At the same time, in the specified system of blood groups in both groups of experimental animals, antigen "a" is characterized by the highest frequency, the lowest occurrence is A2 antigen, and animals with A1 antigen took an intermediate position.

The EAB blood group system is represented by 11 antigens. In the specified system of blood groups, $\mathrm{O}^{1}$ antigen is distinguished by the highest frequency of occurrence, which is similar in both groups of experimental animals and is 70.7\%. In both groups of animals, $\mathrm{O}_{3}$ and $\mathrm{Y}_{2}$ antigens also differ in high frequency, somewhat lower than the previous antigen, but amounting to 66.7 and 60.0 for $\mathrm{O}_{3}$ antigen, and 62.7 and $60.0 \%$ for $\mathrm{Y} 2$ antigen. At the same time, G// and $\mathrm{O} 2$ antigens differ in the lowest frequency, its specific gravity was insignificant. Comparison of groups of experimental animals for antigenic differences showed that Holstein breed cows of reproduction from the USA have a higher frequency of such antigens as $\mathrm{E}_{3}{ }^{\prime}, \mathrm{O}_{3}$ и $\mathrm{I}_{1}$ compared to animals of reproduction of Agro-Soyuz LLC Along with this, the second group animals were distinguished by a higher frequency of antigens $\mathrm{G}_{2}, \mathrm{G}^{/ /}, \mathrm{O}_{2}, \mathrm{P} 1$ compared to the first group animals.

The EAC blood group system is represented by five antigens, among which $\mathrm{C}_{1}$ antigen was the most frequent, its proportion was $77.3 \%$ in US cows and $76.0 \%$ in Agro-Soyuz LLC reproductive animals. In this system of blood groups in both groups of experimental animals, some antigens have similar frequency values. These features are characteristic of antigens $R_{2} C_{1}, X_{2}$. At the same time, differences in the frequency of $C_{2}$ antigen manifestation in favor of the first group of cows are observed between compared groups of experimental animals. The indicated superiority of the first group animals over the second group animals in terms of $\mathrm{C}_{2}$ antigen frequency is $8.0 \%$. However, the opposite tendency is 
observed in $\mathrm{W}$ antigen frequency, the second group animals in terms of $\mathrm{W}$ antigen frequency exceeded the first group animals by $5.4 \%$.

The EAF blood group system is represented by two antigens, where $\mathrm{F}$ antigen frequency in both groups of experimental animals is $100 \%$, i.e. all analyzed animals contain the specified antigen in their genotype. In the analyzed groups of experimental animals, $\mathrm{V}$ antigen frequency is insignificant and ranges within 5.3-6.7\%.

The EAS blood group system is represented by two antigens, of which $\mathrm{S}_{1}$ antigen has a higher and similar frequency in both groups, amounting to 33.3 and $34.7 \%$, respectively. The second group animals were characterized by a higher frequency of $\mathrm{H}^{\|}$antigen compared with animals of the first group, the indicated difference is $2.6 \%$.

Of all analyzed blood group systems, the greatest differences between compared groups of animals were detected for the antigens of EAZ blood group system. In the first group animals, $Z$ and $z$ antigens of this system are manifested with a much lower frequency compared with the second group animals. The indicated difference for the antigens of this blood group system is $21.4-73.3 \%$. At the same time, in this system of blood groups in both groups of experimental animals, $\mathrm{z}$ antigen has a higher frequency, amounting to 70.7 and $144.0 \%$, respectively, compared to $\mathrm{Z}$ antigen.

One $\mathrm{T}_{2}$ antigen was detected in the EAT blood group system. It is worth mentioning that a feature of this herd and the analyzed groups of animals is the low frequency of $\mathrm{T}_{2}$ antigen in the EAT blood group system, which is 4.0 and $5.3 \%$, respectively.

Along with the study of frequency of antigen distribution in the Holstein breed animals, we analyzed the data on the milk productivity of cows selected in the group of cowsmothers o bulls, showing the genetic potential of productivity in breeding conditions (Table 2).

It was found that Holstein cows selected for the group of bull mothers were distinguished by high productivity indicators. In this group of cows, milk yield for 305 days of lactation is $9657 \mathrm{~kg}$ with sufficient variability indicators for breeding, i.e. a standard deviation of $1787 \mathrm{~kg}$ and a coefficient of variation of $18.5 \%$. The presented data on the realization of the genetic potential of productivity suggests the idea of developing a new experimental high fat content milk line of Holstein cattle, as evidenced by rather high values of the fat content in milk at the level of $4.16 \%$ and high values of this sign variability.

Table 2. Performance indicators of the best cows in a herd $(n=20)$.

\begin{tabular}{|c|c|c|c|}
\hline \multirow{2}{*}{ Indicator } & \multicolumn{3}{|c|}{ Parameters } \\
\cline { 2 - 4 } & $\mathbf{X} \pm \mathbf{m}_{\mathbf{x}}$ & $\boldsymbol{\delta}$ & $\mathbf{C}_{\mathbf{v}}$ \\
\hline $\begin{array}{c}\text { Milk yield for 305 days of } \\
\text { lactation, } \mathrm{kg}\end{array}$ & $9657 \pm 410$ & 1787 & 18.5 \\
\hline Fat content of milk, \% & $4.16 \pm 0.08$ & 0.37 & 8.8 \\
\hline Protein content of milk & $3.26 \pm 0.01$ & 0.06 & 1.96 \\
\hline
\end{tabular}

At the present stage in scientific research, considerable attention is paid to the techniques and methods of accelerated selection of farm animals according to the leading economically useful features, analysis of international experience in formation of new animal types under the influence of genetic and paratypical factors. At the same time, the issues of increasing the fat-milk content of the Holstein breed base on promising lines and families are still to be developed. In this regard, the problems associated with increase in implementation of the model animal potential. There are no such scientific studies on the massif of the Holstein breed on the North Caucasian Federal District farms.

These tables also characterize high protein-milk content of the bovine-producing composition of this herd cows, which is $3.26 \%$. 


\section{Conclusions}

In general, Holstein cows of different reproduction revealed differences in antigen carriage, indicating the preservation of sufficient genetic heterogeneity for targeted selection and breeding to increase the milk productivity of animals.

\section{References}

1. T. T. Tarchokov, Z. M. Aisanov, S. F. Sukhanova, A. A. Mishhozhev, D. S. Balpanov, IOP Conference Series: Earth and Environmental Science, 341(1) (2019)

2. A. A. Mishhozhev, M. G. Tleinsheva, Z. M. Aisanov, T. T. Tarchokov, Zootechnics, 11, 24 (2017)

3. A. A. Zhilyaev, T. T. Tarchokov, I. G. Sudorgina, R. Z. Abdulkhalikov, M. G. Tleinsheva, D. S. Balpanov, A. A. Kogotyzhev, Zootechnics, 9, 8 (2020)

4. T. T. Tarchokov, Zootechnics, 5, 27 (1996)

5. M. O. Baytaev, Ts. B. Kagermazov, T. T. Tarchokov, Agrarian Russia, 1, 28 (2013)

6. I. M. Dunin, S.E. Tyapugin, R. K. Meshcherov, V. P. Khodykov, Sh. R. Meshcherov, N. S. Nikulkin, Zootechnics, 2, 5 (2020)

7. A. T. Mysik, Zootechnics, 1, 2 (2010)

8. O. A. Basonov, N. P. Shkilev, A. O. Basonova, N. I. Ivanova, S.G. Arutyunyan, Zootechnics, 10, 6 (2019)

9. O. A. Basonov, N. E. Pavlova, Zootechnics, 11, 11 (2018)

10. N. A. Kravchenko, Farm Animal Breeding (1973) 